\title{
Overcoming adversity: Insights into an acute hospital service of supported viewing for families bereaved during the Covid-19 pandemic
}

\section{Dr Wendy Marina Walker}

The Royal Wolverhampton NHS Trust wendy.walker30@nhs.net

\section{Ruth Horton}

The Royal Wolverhampton NHS Trust

\section{Jennifer Jones}

The Royal Wolverhampton NHS Trust

\section{Julie Morrell}

The Royal Wolverhampton NHS Trust

\section{Elaine Roberts}

The Royal Wolverhampton NHS Trust

Keywords: bereaved, deceased, hospital, pandemic, supported, viewing

\section{Implications for practice}

- Support for family members closely affected by a patient's death is an essential part of acute hospital services.

- Grief theories and research evidence suggests bereaved people may take comfort from viewing the deceased person, but ultimately this is a personal decision.

- Arrangements for viewing the deceased person must include family-centred preparation, and the provision of psychological support for both the recipients and providers of care.

- In addition to quiet reflective time with the deceased person, prayerful remembrances at the time of viewing may be a source of comfort and peace for the bereaved.

\section{Abstract}

The number of people bereaved due to the Covid-19 pandemic is a major health and social care concern. At a time of unprecedented demand on acute and critical care services, restricted family presence to reduce transmission of the disease had a profound impact on the way bereavement support could be provided in the hospital setting. In response, relatively rapid adaptions to practices were required. This paper provides inspiration and guidance on an acute hospital initiative designed to address the emotional needs of the immediately bereaved. The core features of a supported viewing service are presented through the lens of key employees who played a central role in its development and delivery, and with reference to the prevailing literature. Formal evaluation of the service through qualitative inquiry is recommended, complementary to anecdotal evidence of appreciative uptake of the service during the pandemic. 


\section{Introduction and background}

Almost a year since the first human cases of coronavirus disease (Covid-19) emerged in late December 2019 in Wuhan, China, the United Kingdom (UK) became the first country in Europe to pass 100,000 Covid-19 related deaths (BBC News, 2021). A year-to-date national analysis of deaths registered in England and Wales shows that most patients have died in hospitals (Office for National Statistics, 2021). Normally the patient care provider will be a bereaved family's key point of contact (National Quality Board, 2018) and responsibility rests with service providers to ensure that systems are in place for people closely affected by a death (National Institute for Health and Care Excellence, 2017). Essentially it is the duty of healthcare staff to ensure family needs are actively explored, respected and met as far as possible (Leadership Alliance for the Care of Dying People, 2014). In an outbreak, patient care takes precedence, but the wellbeing of the family is also an important priority (Papadimos et al, 2018). Indeed, it has been asserted that family support is more, not less, important during a crisis (Hart et al, 2020).

In the UK, people report that the concepts of choice and control are important to their experience of dying, death and bereavement (The Choice in End of Life Care Programme Board, 2015). However, restrictions to curb the spread of Covid-19 have unavoidably affected personal freedom and choice. Knowledge of previous pandemics shows that multiple losses may be experienced, both related to death itself and in terms of disruption to social norms, rituals, and mourning practices (Mayland et al, 2020). Likewise, a recent research report revealed multiple losses for people bereaved in the UK during the Covid-19 pandemic (Marie Curie, 2021). With particular reference to care after death, customary practices, including preparation, personalisation and participation in funeral services and visitations were either limited or prohibited in an attempt to control community transmission of the virus (Centers for Disease Control and Prevention (CDC), 2020). For some bereaved people, choice was also affected by a protective need to self-isolate or shield. Consideration must therefore be given to the impact of Covid-19 restrictions on bereaved people and the provision of bereavement care and support (Chalmers, 2021; Pearce et al, 2021). This is necessary regardless of whether the person's death was due to Covid-19 or some other cause (CDC, 2020).

Support for the bereaved family in a hospital setting includes viewing arrangements. This paper describes the core features of a supported viewing service, designed to address the emotional needs of the immediately bereaved during the Covid-19 pandemic. The service innovation took place in an acute hospital in the Midlands, UK. The reflective accounts of frontline staff involved in the design and delivery of the service are presented, together with numerical data reporting bereaved family uptake. The staff reflective contributions are those of a chaplaincy team leader, a bereavement nurse, a directorate manager for patient services (mortuary), and a group manager for surgical and patient services. The paper primarily takes the form of a critical narrative to provide experiential insights into the successes and challenges of the service, and related implications for practice, service evaluation and research. The contribution of experiential knowledge for practice adds to the limited literature and research available on this important topic.

\section{Viewing the deceased person}

Viewing the body of the deceased person is a mourning tradition in some cultures, and ultimately a personal decision of the bereaved (Charles-Edwards, 2005). For example, viewing of the deceased before burial is customary for Muslims, subject to individual custom, variation and preference (Alladin, 2015). The practice is considered to fulfil a bereaved person's need to say goodbye (Paul, 2019) and is an important show of respect for some ethnic and religious groups. In our experience of caring for bereaved families in a busy acute hospital, the Covid-19 pandemic left people feeling confused, isolated and disempowered at this most vulnerable time. Many families reported saying goodbye to their relative at home as they were admitted to hospital and never seeing them in person again. Some families also had little time to prepare for a loved one's death following a period of sudden and unanticipated illness due to Covid19. Various members of our hospital multi-faith chaplaincy team vividly recall family members' reaction of disbelief about their relative's death and expressed need to attend a supported viewing.

Studies have shown that one reason for adult bereaved family members wanting to view, and a 
perceived benefit of having viewed, was an ability to comprehend the death had happened (Mowll, 2007; Mowll et al, 2016). Even in traumatic circumstances, people bereaved, who had made a choice to either view or not to view their deceased relative suggested it had been the right decision for them, with viewing perceived to have helped bring home the reality of the death (Chapple \& Ziebland, 2010). Similarly, suddenly bereaved family members have discussed the role of viewing as grounding them in the reality and the circumstances of the death (Harrington \& Sprowl, 2012). Visual confirmation has a role to play in grief reconciliation (Paul, 2019), and acceptance of the loss is an identified task of mourning for healthy adaptation (Worden, 2018). As stated by Raphael (1995) 'The recognition of the person in death provides a certain sad reality that can then be accepted' (p32).

Before the outbreak of the Covid-19 pandemic, viewing in our hospital commonly took place in the ward/department shortly after patient death, or in a viewing room attached to the hospital mortuary. On average, 20 viewings were arranged and facilitated by our mortuary team each month. However, with the pandemic came widespread disruption to services and care. Care after death guidance, updated in response to Covid-19, acknowledged that 'viewing may not be permitted in acute hospitals in order to reduce infection risk' (Hospice UK, 2020, p20). Some funeral firms also had restrictions in place that limited or prevented viewing in a Chapel of Rest (National Association of Funeral Directors, 2020). Of note, however, guidance for care of the deceased with suspected or confirmed coronavirus (Covid-19) advised that viewing is permitted 'when overseen or undertaken by those trained in handling bodies of the deceased' (Public Health England, 2021).

\section{Overcoming adversity: Initiating a supported viewing service}

To address the felt impact of the pandemic on our usual procedures for viewing, and to meet the needs of grieving families, a dedicated working group initiated a service of supported viewing. Essentially, the service was a redesign of this existing provision, born out of the challenges of the pandemic and accompanying opportunities for change. In the following section, we describe three creative features of the service:
1 To restore the concept of choice, the hospital chaplaincy team, working within a wider multidisciplinary team, offered supported viewing with or without prayer, or individual prayer for the deceased without the family present. The aim at all times was to be inclusive and responsive to families in both a faith-specific and culturally competent manner. Both ordained and lay chaplains were able to offer support and the chaplaincy team at all times were mindful of gender preference by offering the choice of a male or female chaplain wherever possible. Individual prayer for the deceased without the family present was normally facilitated every morning by a member of the chaplaincy team. The option to be accompanied by a bereavement nurse was also offered.

2 Families who requested a supported viewing were asked if they would like a knitted heart to be placed with their loved one and to receive the matching heart as a keepsake. Matching pairs of hand-made knitted hearts became a symbol of the Covid-19 pandemic to help connect families with their loved ones. We are indebted to Swindon-based nurse Laura Kirkby-Deacon for launching this appeal (Healthwatch, Swindon, 2020), and to our local community for their donations to this cause.

3 A prayer card personalised with the name of the deceased was also offered to each family at the end of the viewing or sent by post to families who said they would like to receive this. The cards were designed by the chaplaincy team using their own photography and were produced in-house. These were offered from the Christian, Sikh and Hindu faith traditions and included contact details for the hospital's chaplaincy and bereavement nurse, and the local branch of a national charity, Cruse Bereavement Care.

Other design features of the service reflected commonly understood procedures for viewing the deceased person, but with heightened awareness of the unfolding public health crisis. Due consideration was given to the safety and wellbeing of those present in the context of the environment of care in which a viewing would take place.

Our individualised and culturally sensitive viewing service is underpinned by the principles of the Swan initiative that we adopted as a National Health Service (NHS) Trust in 2015. First launched in Greater Manchester, Swan is a 
comprehensive model of care and support at the end of life, and into bereavement and beyond (Murphy, 2019). Swan care is reflected in all our wards and departments, and this extends to our mortuary facilities which we chose to name The Swan Suite. Our viewing area is a small, comforting room with dimmed lighting and pictures on the wall to make it look homely. A large window separates a waiting room from the viewing room, with blinds on the side of the waiting room. This window provided a protective screen that enabled us to safely offer a supported viewing service. Importantly, we were clear in our initial communication with families about possibilities when viewing due to pandemic-related restrictions, in that the viewing could only take place behind the viewing window. Also, that infection prevention and control procedures would be strictly followed, including face mask, hand sanitiser and social distancing practices.

Before viewing, families were guided to a temporary waiting area and asked to provide the deceased's name, date of birth and address by completing a Swan Suite card; information for use by mortuary staff to check the identification of the deceased. Subsequently, they were greeted by a member of the supported viewing team, and the viewing process was explained to them. A familycentred approach to viewing and information exchange arguably play a critical role in determining what the bereaved person understands, expects and wants the viewing experience to be like. For example, facilitating a careful discussion on the appearance of the deceased can allow for an informed choice (Mowll, 2007; Healthtalk, 2019) and facilitate mental preparation for the bereaved person (Omerov et al, 2014). Mowll (2017, p109) advocates 'sensitively paced and dosed information' in preparation to view, consistent with the capacities, needs and wishes of the grieving family. Our family preparation for viewing included an explanation as to where their relative would be placed beneath the viewing window, and guidance on perhaps where best to stand or sit. Consideration was given to the family experience of seeing their deceased relative by slowly raising the blind to the viewing room, having first determined that they felt ready to proceed. For families who requested supported viewing with prayer, raising of the blind was co-ordinated with the commencement of prayer. Families were also offered time in private with their deceased relative, with the reassurance of knowing the supporting staff person was just outside the viewing room. Lowering of the blind signified the end of the viewing appointment, a practice also co-ordinated with prayer in supported viewings by a member of the chaplaincy team.

\section{A dedicated team approach}

The Covid-19 pandemic has shown that crisis breeds creativity and action (Bleich et al, 2020). Initiation of the supported viewing service was a tremendous effort from very dedicated individuals, who, from the start, wanted the service to be the best that it could be despite the challenging circumstances of the pandemic. At the planning stage, Estates Development and Estates and Facilities were consulted to ensure that viewings could be befittingly accommodated. Measures were taken to conceal the view of additional mortuary storage capacity units, and any necessary additional signage was provided. A combination of chaplaincy, bereavement, mortuary, portering, security and housekeeping staff worked collaboratively to deliver the service, together with essential administrative personnel. Every bereaved family was telephoned by a nurse who was redeployed to assist the viewing service. This contrasts with interim findings of a survey which found that $45 \%$ of people bereaved in the UK since March 2020 were not contacted by the hospital or care provider following a bereavement (University of Bristol, 2020). A good practice recommendation is to assist families in finding a viewing room adjacent to a mortuary (Hospice UK, 2015). On the day of viewing, support was on hand from a member of the hospital security team who provided the family access to a car parking facility, and subsequently accompanied them to a temporary waiting area, having first checked that this had been cleaned and replenished by housekeeping staff. On-site security teams have played a crucial role in keeping the environment safe and secure during these precarious times (Benoit, 2021). We recall their compassion, and a caring protective presence that may have afforded our families reassurance.

\section{Uptake of the supported viewing service}

An analysis of routine mortuary, bereavement and chaplaincy services' activity data revealed that during the peak period of the first wave of the 
pandemic, ie in the timeframe 14 April to 31 July 2020, 560 families were offered the service. The uptake was $404(72 \%)$, of which, $327(81 \%)$ families opted for chaplaincy team faith-based encounters/prayers. This comprised 128 viewings with prayer and 199 prayers without the family present (Walker et al, 2021). This we feel is a significant finding, particularly within a society that we are told is becoming increasingly secular (Sherwood, 2019). The high uptake of prayer also supports the perspective of Giordan \& Woodhead (2015) who suggest that levels of prayer remain high, even among those who have abandoned organised religion.

Theologically, prayer is an expression of most religions. It is an activity increasingly recognised by scholars for its psychological function and potentially personal benefits (ap Siôn \& Francis, 2009; Mountain, 2014). In practice, our experiences during the Covid-19 pandemic suggest that prayerful remembrances for those who have died may be a source of comfort and peace for the bereaved. We observed that families who initially appeared to be requesting prayer solely for their loved one, subsequently proceeded to seek chaplaincy support and requested additional prayer cards for family members and friends. In total, 840 personalised prayer cards were produced.

Matching pairs of knitted hearts, donated to the hospital towards the end of April 2020 onwards, were accepted by 143 bereaved families.

\section{Implications for practice, service evaluation and research}

A common thread in the healthcare literature is the headline of service change and innovation as a positive legacy of Covid-19 (NHS Confederation, 2020; Care Quality Commission, 2021; McKimm, 2021). New systems and processes were introduced in extraordinary circumstances, and the challenge is to embed and build on the seemingly beneficial features of our viewing service in its new form. We anticipate the number of family requests to view the deceased person at the hospital may decrease as funeral directors gradually re-introduce their own viewing service. However, information will continue to provide the basis for families to make an informed choice about if, when and where to view. During the pandemic, the hospital bereavement service webpage was a source of virtual communication with families at a time of restricted physical presence. We favour retaining this as an information resource to supplement a bereavement booklet and conversation with the family. The importance of preparation for family viewing and the provision of psychological care and support before, during and after the viewing should not be underestimated. This applies to all involved in this sensitive encounter; both recipients and providers of care. The support which forms an integral part of our viewing service is first and foremost for grieving families, but also embraces collegiate care for each other. In addition, the families of patients who died at our hospital have access to a virtual bereavement hub, and information about local bereavement service organisations. For staff, our trust employee assistance programme offers a free 24-hour advice and counselling service.

Evaluation is an important part of organisational change in health services (McDonnell et al, 2006), particularly when the intervention represents an innovative or novel approach (Public Health England, 2018). The National Institute for Health Research (2019) encourages organisations to embrace all forms of feedback originating from both informal and formal sources. Supplementary to the routine collection of uptake data, it has been truly humbling to hear from families how much comfort they have taken from the supported viewing service. Appreciation was expressed in a variety of ways such as telephone calls to the hospital bereavement centre, by sending thank you cards, and in charitable donations to the hospital. We value and respect the informal feedback received from families, and its contribution to affirming how families positively viewed the service provided. More formally, consideration could be given to undertaking a service evaluation of its intended aims or an internal audit against predetermined national standards of bereavement care (Bereavement Services Association and Cruse Bereavement Care, 2013).

The small body of existing evidence on the function and practice of viewing the deceased person suggests a need for further research. The inventive nature of the supported viewing service lends itself to new knowledge and learning through qualitative feedback methods. Possible areas of inquiry include the bereaved family experience of hospital-based post-death support in the context of Covid-19, the significance of choice for grieving families, their reasons for, and emotional reactions to viewing their deceased relative, and the subjective effects of prayer and pastoral support. 


\section{Conclusion}

Appropriate family support around the time of death and afterwards is essential to creating the foundations for a healthy bereavement. The supported viewing service presented in this paper serves as an example of the creativity that has been unleashed by individuals and teams in the wake of Covid-19. The experiential insights of staff and bereaved family uptake of this service provide inspiration to further understand the role of choice in the experience of grief, and the value of viewing as a bereavement intervention, with or without personal presence and prayer. With each day of the Covid-19 pandemic, we witness the tragic and cumulative loss of life, and the emotional pain of personal grief. It has been our privilege to create and deliver something very precious and meaningful to bereaved families at this most challenging time.

\section{References}

Alladin W (2015) The Islamic way of death and dying: Homeward bound. In: CM Parkes, P Laungani \& B Young (eds) Death and bereavement across cultures (2nd ed). Routledge.

ap Siôn T \& Francis LJ (2009) The psychology of prayer: A review of empirical research. In: $\mathrm{M}$ de Souza, LJ Francis, J O'Higgins-Norman \& D Scott (eds) International handbook of education for spirituality, care and wellbeing. International handbooks of religion and education, vol 3. Springer.

BBC News (2021) Covid deaths: 'Hard to compute sorrow' of 100,000 milestone - PM. Available at: www.bbc.co.uk/news/uk-55814751 [accessed 10 May 2021].

Benoit M (2021) The role of a security guard during COVID-19. Available at: www.ifsecglobal.com/global/therole-of-a-security-guard-during-covid-19/ [accessed 10 May 2021].

Bereavement Services Association and Cruse Bereavement Care (2013) Bereavement Care Service Standards. Available at: www.cruse.org.uk/organisations/bereavement-care-servicestandards/ [accessed 2 December 2021].

Bleich MR, Smith S \& McDougle R (2020) Public policy in a pandemic: A call for leadership action. The Journal of Continuing Education in Nursing, 51(6) 250-252. https://doi.org/10.3928/00220124-20200514-03.

Care Quality Commission (2021) Innovation and inspiration: examples of how providers are responding to coronavirus (COVID-19). Available at:

https://www.cqc.org.uk/publications/innovationinspiration-examples-how-providers-are-responding-corona virus-covid-19 [accessed 2 December 2021.

Centers for Disease Control and Prevention (2020) Funeral guidance for individuals and families. Available at: www.cdc.gov/coronavirus/2019-ncov/daily-lifecoping/funeral-guidance.html [accessed 10 May 2021].
Chalmers A (2021) 'The ripple effect of the pandemic is huge.' Blog post: The impact of the Covid-19 Pandemic on bereaved people. Available at:

www.childbereavementuk.org/blog/the-impact-of-covid19-on-bereaved-people [accessed 10 May 2021].

Chapple A \& Ziebland S (2010) Viewing the body after bereavement due to a traumatic death: Qualitative study in the UK. British Medical Fournal, 340, c2032. https://doi.org/10.1136/bmj.c2032.

Charles-Edwards D (2005) Handling death and bereavement at work. Routledge.

Giordan G \& Woodhead L (2015) A sociology of prayer. Routledge.

Harrington C \& Sprowl B (2011-2012) Family members' experiences with viewing in the wake of sudden death. OMEGA - Journal of Death and Dying, 64(1) 65-82. https://doi.org/10.2190/om.64.1.e.

Hart JL, Turnbull AE, Oppenheim IM \& Courtright KR (2020) Family-centered care during the COVID-19 era Fournal of Pain and Symptom Management, 60(2) e93-e97. https://doi.org/10.1016/j.jpainsymman.2020.04.017.

Healthtalk (2019) Bereavement due to traumatic death: Viewing the body. Accessed on 10 May from: https://healthtalk.org/ bereavement-due-traumatic-death/viewing-the-body

Healthwatch, Swindon. News - 14 April 2020. Knitting hearts with GWH to help those who lose loved ones. Available at: www.healthwatchswindon.org.uk/news/2020-0414/knitting-hearts-gwh-help-those-who-lose-loved-ones [accessed 10 May 2021].

Hospice UK (2015) Care after death: Guidance for staff responsible for care after death. Available at:

https://derbyshire.eolcare.uk/content/documents/uploads /toolkit-docs/Care-after-death_2nd-edition_V1.pdf [accessed 8 November 2021].

Hospice UK (2020) Third edition care after death: Guidance for staff responsible for care after death. Available at: www.hospiceuk.org/what-we-offer/clinical-and-caresupport/clinical-resources [accessed 10 May 2021].

Leadership Alliance for the Care of Dying People (2014) One chance to get it right: Improving people's experience of care in the last few days and hours of life. Available at:

https://assets.publishing.service.gov.uk/government/uploa ds/system/uploads/attachment_data/file/323188/One_c hance_to_get_it_right.pdf [accessed 10 May 2021].

Marie Curie (2021) Better end of life 2021: Dying, death and bereavement during Covid-19 Research Report. Available at: https://www.mariecurie.org.uk/globalassets/media/docu ments/policy/policy-publications/2021/better-end-of-liferesearch-report.pdf [accessed 2 December 2021].

Mayland CR, Harding AJE, Preston N \& Payne S (2020) Supporting adults bereaved through COVID-19: A rapid review of the impact of previous pandemics on grief and bereavement. Fournal of Pain and Symptom Management, 60(2) e33-e39. https://doi.org/10.1016/j.jpainsymman.2020.05.012

McDonnell A, Wilson R \& Goodacre S (2006) Evaluating and implementing new services. British Medical Journal, 332(109). https://doi.org/10.1136/bmj.332.7533.109 
McKimm A (2021) Editorial: Innovation will help us leave a positive health legacy from COVID-19. BMJ Innovations, 7, 247-248.

Mountain V (2014) Research into children's perception of prayer: The meaning and function of prayer for children. Published version of $\mathrm{PhD}$ Research. University of Divinity, Australia. Available at: https://repository.divinity.edu.au/ 1600/ [accessed 10 May 2021].

Mowll J (2017) Supporting family members to view the body after a violent or sudden death: A role for social work. Fournal of Social Work in End-of-Life \& Palliative Care, 13(2-3) 94-112. https://doi.org/10.1080/15524256.2017.1331182

Mowll J (2007) Reality and regret: viewing or not viewing the body after a sudden death. Bereavement Care, 26(1) 3-6. https://doi.org/10.1080/02682620708657676.

Mowll J, Lobb EA \& Wearing M (2016) The transformative meanings of viewing or not viewing the body after sudden death. Death Studies, 40(1) 46-53.

https://doi.10.1080/07481187.2015.1059385.

Murphy F (2019) Care through end of life into bereavement. Nursing Standard 34(6) 43.

https://doi.org/10.7748/ns.34.6.43.s28.

National Association of Funeral Directors (2020) Advice for the public: Frequently asked questions. Available at: https://nafdcovid19.org.uk/advice-for-thepublic/frequently-asked-questions/ [accessed 10 May 2021].

National Institute for Health and Care Excellence (2017) End of life care for adults. Quality statement 14: Care after deathbereavement support. Available at:

https://www.nice.org.uk/guidance/qs13/documents/previ ous-version-of-quality-standard [accessed 2 December 2021].

National Institute for Health Research (2019) Themed reviere. Improving care by using patient feedback. NIHR Dissemination Centre. Available at: https://content.nihr.ac.uk/nihrdc/ themedreview-04327-PE/Patient-Feedback-WEB.pdf [accessed 10 May 2021].

National Quality Board (2018) Learning from deaths. Guidance for NHS trusts on working with bereaved families and carers. Available at: www.england.nhs.uk/publication/learningfrom-deaths-guidance-for-nhs-trusts-on-working-with-berea ved-families-and-carers/ [accessed 10 May 2021].

NHS Confederation (2020) What we have learned so far: Best practice and innovation during COVID-19. Available at: www.nhsconfed.org/resources/2020/11/what-welearned-best-practice-and-innovation-during-covid 19 [accessed 1 June 2021).

Office for National Statistics (2021) Deaths registered weekly in England and Wales, provisional: week ending 23 April 2021. Available at: www.ons.gov.uk/people populationandcommunity/birthsdeathsandmarriages/deat hs/bulletins/deathsregisteredweeklyinenglandandwalespro visional/weekending23april2021 [accessed 10 May 2021].

Omerov P, Steineck G, Nyberg T, Runeson B \& Nyberg U (2014) Viewing the body after bereavement due to suicide: a population-based survey in Sweden. PLoS One 9(7) e101799. https://doi.org/10.1371/journal.pone.0101799.
Papadimos TJ, Marcolini EG, Hadian M, Hardart GE, Ward N, Levy MM, Stawicki SP \& Davidson JE (2018) Ethics of outbreaks position statement. Part 2: FamilyCentered Care. Critical Care Medicine 46(11) 1856-1860. https://doi.org/10.1097/CCM.0000000000003363

Paul RJ (2019) Viewing the body and grief complications: The role of visual confirmation in grief reconciliation. In: GR Cox, RA Bendiksen \& RG Stevenson (eds). Complicated grieving and bereavement: Understanding and treating people experiencing loss. Routledge. eBook,

https://doi.org/10.4324/9781315224923

Pearce C, Honey JR, Lovick R, Greamer NZ, Henry C, Langford A, Stobert M \& Barclay S (2021) 'A silent epidemic of grief': a survey of bereavement care provision in the UK and Ireland during the COVID-19 pandemic. BMJ Open 11:e046872. https://doi.org/10.1136/bmjopen2020-046872.

Public Health England (2021) Guidance for care of the deceased with suspected or confirmed coronavirus (COVID-19). Available at: https://www.gov.uk/government/publications/covid19-guidance-for-care-of-the-deceased/guidance-for-care-of -the-deceased-with-suspected-or-confirmed-coronaviruscovid-19 [accessed 2 December 2021].

Public Health England (2018) Introduction to evaluation in health and wellbeing. Available at: Public Health England (2021) Guidance for care of the deceased with suspected or confirmed coronavirus (Covid-19). Available at:

https://www.gov.uk/guidance/evaluation-in-health-andwellbeing-introduction [accessed 2 December 2021].

Raphael B (1995) The anatomy of bereavement: A handbook for the caring professions. Routledge. eBook https://doi.org/10.4324/9780203450673.

Sherwood H (2019) UK secularism on rise as more than half say they have no religion. Available at:

www.theguardian.com/world/2019/jul/11/uk-secularismon-rise-as-more-than-half-say-they-have-no-religion [accessed 10 May 2021].

The Choice in End of Life Care Programme Board (2015) What's important to me: A review of choice in end of life care. Available at: https://assets.publishing.service.gov.uk/ government/uploads/system/uploads/attachment_data/fil e/407244/CHOICE_REVIEW_FINAL_for_web.pdf [accessed 10 May 2021].

University of Bristol (2020) Exceptional challenges of bereavement during the pandemic highlighted in interim findings. Press release: 1 December 2020. Available at: www.bristol.ac.uk/neuroscience/news/2020/bereavementcovid.html [accessed 10 May 2021].

Walker WM, Horton R, Jones J, Morrell J \& Roberts E (2021) Viewing the deceased person: bereaved family uptake of a new service in the wake of COVID-19 restrictions. BM7 Supportive \& Palliative Care, 11:A19-A20.

Worden JW (2018) Grief counseling and grief therapy: A handbook for the mental health practitioner (5th ed). Springer Publishing Company. 